\title{
Vpliv tradicionalne zasnove naselij na urbanistično oblikovanje in načrtovanje: primer nigerijskega mesta Zaria
}

Avtorja na primeru starega dela nigerijskega mesta Zaria, ki se je razvijal med 11. in 19. stoletjem, proučujeta vpliv tradicionalne zasnove naselij na načrtovanje novih mestnih predelov. Njuna glavna teza je, da so bile nekatere prvine stare zasnove naselij vključene v novi del mesta. Ob pregledu literature analizirata razvoj mesta, pri čemer se osredotočata na tradicionalno arhitekturo Havsov in zasnovo njihovih naselij ter vpliv te arhitekture in zasnove na prostorsko ureditev. $\mathrm{Z}$ zemljevidi, skicami in preglednicami ponazorita, kako je bogata tradicija Havsov vplivala na urbanistično oblikovanje in načrtovanje mesta.
Izsledki raziskave kažejo, da so nekatere tradicionalne zasnove naselij vplivale na urbanistično oblikovanje mesta, saj je bila ljudska arhitektura postopno vključena v regulacijske načrte novih mestnih predelov. Avtorja v sklepnem delu ugotavljata, da se lahko arhitekti, načrtovalci in investitorji veliko naučijo iz študije primera mesta Zaria.

Ključne besede: tradicionalna naselja, ljudska arhitektura, urbanistično oblikovanje in načrtovanje, kultura Havsov 


\section{Uvod}

Bivališča so namenjena zadovoljevanju osnovnih človekovih potreb, zlasti zagotavljanju strehe nad glavo, varnosti in udobja. Kot navaja Astrolabe (2002), se ustvarjanje doma z vidika izbora lokacije, načrtovanja in gradnje v praksi od države do države razlikuje (Dobronravin, 2013; Barau idr., 2015). V povezavi z naselji Dmochowski (1990) poudarja, da lahko sodobne oblike stanovanjske gradnje vključujejo tradicionalno arhitekturo in zasnovo naselij, ki se mešata s sodobnimi oblikami in jih oblikujeta. Številna etnična in geografska območja v Nigeriji, vključno z osrednjimi, vzhodnimi in zahodnimi regijami, imajo tradicionalno arhitekturo in obliko poselitve, ki se od območja do območja razlikuje. Tradicionalna arhitektura Havsov je nekaj edinstvenega (Buchanan in Pugh, 1995). Prostorska razporeditev njihovih bivališč in odprtega prostora se je razvijala več generacij, nanjo pa so vplivali številni civilizacijski, kulturni in drugi dejavniki, povezani s tradicijo okolja. Olotuah (2000) navaja, da so lahko nekatere arhitekturne oblike značilne za posamezne etnične skupine in posledično vplivajo na obliko njihovih naselij, Egipčani, Grki in Rimljani so na primer razvijali arhitekturo, namenjeno različnim funkcijam (Hutchison in Sterbenz, 2018). Podobno so tudi Havsi z območja Zarie v severni Nigeriji znani po edinstveni arhitekturi, pri kateri oblika stavb izraža družbene vrednote (Rowan, 1981). Zaria je primer zgodovinskega naselja Havsov, v katerem so zunanji dejavniki, kot so podnebje, lokacija in družbene potrebe, vplivali na izbor materialov, tehnik in okrasja naselja, poleg tega pa še na velikost in razmerje prostorov ter razporeditev hiš (Denyer, 1978).

Avtorja obravnavata oblike in zasnove naselij tega ljudstva ter analizirata njegovo tradicionalno arhitekturo, da bi opredelila značilne urbanistične koncepte, ki jih lahko mestni načrtovalci, arhitekti in investitorji vključijo v sodobne urbanistične projekte. Na primeru starega mestnega jedra Zarie, ki se je razvijalo med 11. in 19. stoletjem, proučujeta vpliv tradicionalnih oblik naselij na načrtovanje novih mestnih predelov. Obravnavata naslednja vprašanja:

1. Kateri so zgodovinski razlogi za razvoj tradicionalnih havških naselij in arhitekture?

2. Kateri dejavniki so vplivali na prostorsko ureditev, obliko in tloris havških naselij?

3. Katera mnenja prevladujejo o vplivu tradicionalnih naselij in arhitekture v Zarii na združevanje starih in novih oblik naselij v sodobnem urbanizmu?

\section{Gradivo in metode}

V tem poglavju je opisano območje raziskave, predstavljene so podobne starejše in novejše raziskave in opredeljeni so razlogi za izbor uporabljene metode zbiranja podatkov. Mesto Zaria je bilo izbrano, ker dobro ponazarja, kaj se lahko urbanisti in drugi strokovnjaki naučijo iz bogate arhitekturne tradicije Havsov ter zasnove in prostorske ureditve njihovih naselij. Metoda zbiranja podatkov je bila podobna tisti, ki so jo uporabili drugi raziskovalci (npr. Faludi, 1979; Taylor, 1998; Deckro in Hebert, 2003). Združevala je etnografijo in paradigmo načrtovalske teorije, ki upošteva tradicionalne in sodobne pristope $\mathrm{k}$ arhitekturi, zasnovam naselij in načrtovanju mest. $\mathrm{Z}$ izbrano raziskovalno metodo sta lahko avtorja pokazala, kako je tradicionalno havško naselje vplivalo na urbanistično oblikovanje in načrtovanje $\mathrm{v}$ Zarii.

\subsection{Izbor proučevanega območja in zbiranje podatkov}

Staro mestno jedro Zarie je primer značilnega naselja Havsov in po mnenju avtorjev eden najboljsih primerov tradicionalnega načrtovanja mest v Zahodni Afriki. V skladu z etnografskimi metodami vključevanja skupnosti v raziskave zgodovinskih naselij (npr. Ibrahim, 2015; Narayanan, 2015) so bili primarni podatki zbrani na podlagi intervjujev s prebivalci Zarie. Primarni in sekundarni podatki so bili potrebni za boljše razumevanje vpliva tradicionalnih havških naselij na arhitekturo, načrtovanje in prostorsko ureditev mesta. Podatki so bili zbrani $\mathrm{v}$ dveh fazah:

- v prvi fazi so bili na podlagi pregleda ustnega izročila in objavljenih informacij zbrani sekundarni podatki. Proučeni so bili stevilni viri, zlasti strokovni članki o tradicionalni arhitekturi in zasnovah havških naselij ter knjižnično gradivo mesta Zarie in tamkajšnje Univerze Ahmaduja Bella;

- v drugi fazi so bili podatki pridobljeni od ključnih posameznikov, kot so tradicionalni vodje, starešine, trgovci, uradniki in raziskovalci oddelka za arhitekturo na Univerzi Ahmaduja Bella. Poudarek je bil na bolǰ̌em razumevanju razvoja naselij in urbanističnega načrtovanja na proučevanem območju.

Z izbranimi raziskovalnimi metodami je bilo mogoče analizirati vpliv zasnove starih naselij na sodobno urbanistično oblikovanje in načrtovanje, kar se ujema z metodami, ki poudarjajo potrebo po upoštevanju zgodovinskih, kulturnih, fizičnih, gospodarskih in družbenih vidikov urbanih sistemov in območij. Pristop temelji na knjigi z naslovom Field instruction: A guide for social work students (Royse idr., 2007), ki vsebuje smernice za opravljanje terenskih raziskav v skupnostih. 
Preglednica 1: Raziskovalna vprašanja, metode, analiza in rezultati

\begin{tabular}{|c|c|c|c|}
\hline Vprašanje & Metoda & Analiza & Rezultat \\
\hline \multirow{4}{*}{$\begin{array}{l}\text { 1) Kateri so zgodovinski razlogi } \\
\text { za razvoj tradicionalnih havških } \\
\text { naselij in arhitekture? }\end{array}$} & - sekundarni viri (11.-19. stol.) & - opisna statistika & \multirow{4}{*}{$\begin{array}{l}\text { prikaz in tipologija arhitekture, } \\
\text { tradicionalnih naselij in } \\
\text { urbanističnega načrtovanja }\end{array}$} \\
\hline & - intervjuji po gospodinjstvih & - analiza trendov & \\
\hline & $\begin{array}{l}\text { - intervjuji s ključnimi } \\
\text { posamezniki }\end{array}$ & $\begin{array}{l}\text { - zgodovinska analiza/analiza } \\
\text { dokumentov }\end{array}$ & \\
\hline & - participativno kartiranje & & \\
\hline \multirow{8}{*}{$\begin{array}{l}\text { 2) Kateri dejavniki so vplivali na } \\
\text { prostorsko ureditev, obliko in } \\
\text { tloris havških naselij? }\end{array}$} & $\begin{array}{l}\text { - splošna raziskava } \\
\text { proučevanega območja }\end{array}$ & $\begin{array}{l}\text { - analiza značilnosti/prostorska } \\
\text { analiza }\end{array}$ & \multirow{8}{*}{$\begin{array}{l}\text { prostorski vzorci in tloris naselij, } \\
\text { arhitekturni slogi in oblika hiš }\end{array}$} \\
\hline & - terenska opazovanja & • analiza dejavnikov združevanja & \\
\hline & • terensko preverjanje izsledkov & starih in novih oblik & \\
\hline & intervjujev & - prostorska analiza & \\
\hline & $\begin{array}{l}\text { • intervjuji s ključnimi posame- } \\
\text { zniki }\end{array}$ & $\begin{array}{l}\text { - analiza dejavnikov združevanja } \\
\text { starih in novih oblik }\end{array}$ & \\
\hline & & - analiza arhitekture/oblike hiš & \\
\hline & & - hitra participativna analiza & \\
\hline & & - tematska analiza & \\
\hline \multirow{5}{*}{$\begin{array}{l}\text { 3) Katera mnenja prevladujejo } \\
\text { o vplivu tradicionalnih naselij in } \\
\text { arhitekture v Zarii na združevanje } \\
\text { starih in novih oblik naselij pri } \\
\text { sodobnem urbanističnem obliko- } \\
\text { vanju in načrtovanju? }\end{array}$} & - intervjuji s ključnimi & - analiza intervjujev & \multirow{5}{*}{$\begin{array}{l}\text { mnenja o vplivu tradicionalnih } \\
\text { naselij in arhitekture v Zarii } \\
\text { na združevanje starih in novih } \\
\text { naselij }\end{array}$} \\
\hline & posamezi & - analiza dejavnikov združevanja & \\
\hline & - deduktivna metoda & starih in novih oblik & \\
\hline & & - prostorska analiza & \\
\hline & & - deduktivna analiza & \\
\hline
\end{tabular}

Vir: avtorja, na podlagi Ibrahim (2015) in Narayanan (2015)

\subsection{Anketiranje}

$\mathrm{Na}$ desetih ključnih točkah v Zarii (blizu mošeje, tržnic in trgovin) so bile s ključnimi posamezniki opravljene ankete o arhitekturi ter urbanističnem oblikovanju in načrtovanju. Vprašanja so se nanašala na uporabljene gradbene materiale, vpliv vere na arhitekturo, verske simbole in značilne okrasne vzorce, sestavo gospodinjstev in prostorsko razdelitev zemljišča posamezne domačije. Navedeni pristop je bil potreben, ker je večina prebivalcev Zarie muslimanov, zaradi česar je dostop do ženskih anketirank otežen. Poleg tega je bilo 63 anket opravljenih z glavno osebo v posameznem gospodinjstvu, pri čemer je morala taka oseba najprej povedati, ali živi v starem ali novem delu mesta.

\subsection{Terenska opazovanja}

Opravljene so bile terenske raziskave havških naselij, sestavljenih iz posameznih gospodinjskih enot s pripadajočimi funkcionalnimi površinami, izsledke pa sta nato avtorja primerjala s starimi skicami iz kolonialnega obdobja. Na tej podlagi sta izdelala ilustracije in skice, prikazane v članku. O pomenu okrasja in podob na pročeljih in vratih sta govorila s ključnimi posamezniki in raziskovalci iz Oddelka za arhitekturo
Univerze Ahmaduja Bella. Navedeno je omogočilo globlji vpogled v vpliv tradicionalne arhitekture in naselij Havsov na sodobno načrtovanje mesta. Tradicionalne oblike naselij sta avtorja prikazala na skicah.

\section{Havška naselja}

Zaria je na južnem robu etničnega havškega ozemlja. Naselja Havsov so bila nekdaj fevdalne mestne države z monarhično obliko vladavine. Obdana so bila z obzidjem, znotraj katerega je bila tržnica. V 14. stoletju se je iz malijskega cesarstva med ljudstvo razširil islam, ki je po mnenju avtorjev obogatil njegovo kulturo. Na začetku 19. stoletja so upravo nad nekdanjimi emirati prevzeli Britanci. Ustanovitev univerze in univerzitetnega naselja je vplivala na tradicionalno arhitekturo in prostorsko ureditev širšega območja Zarie, tudi v Bomu - še enem havškem naselju severno od Zarie.

\subsection{Geografsko in zgodovinsko ozadje havških naselij}

Havška naselja so v savanah običajno blizu rek. Na območju njihove poselitve se včasih gozdnate doline izmenjujejo z ob- 


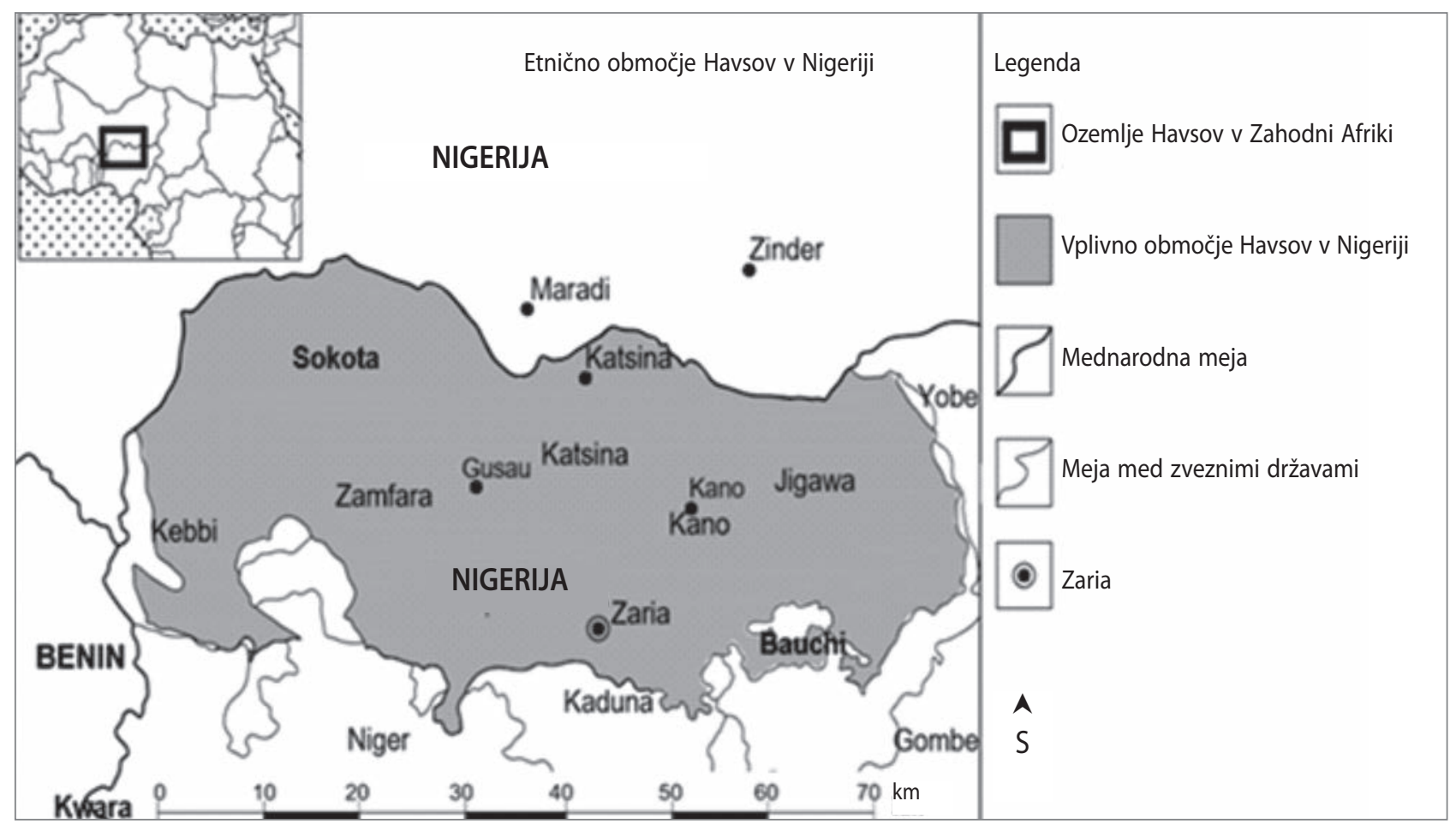

Slika 1: Lokacija Zarie in drugih nekdanjih havških mestnih držav (ilustracija: avtorja, na podlagi Ayodele in Odeyale, 2019)

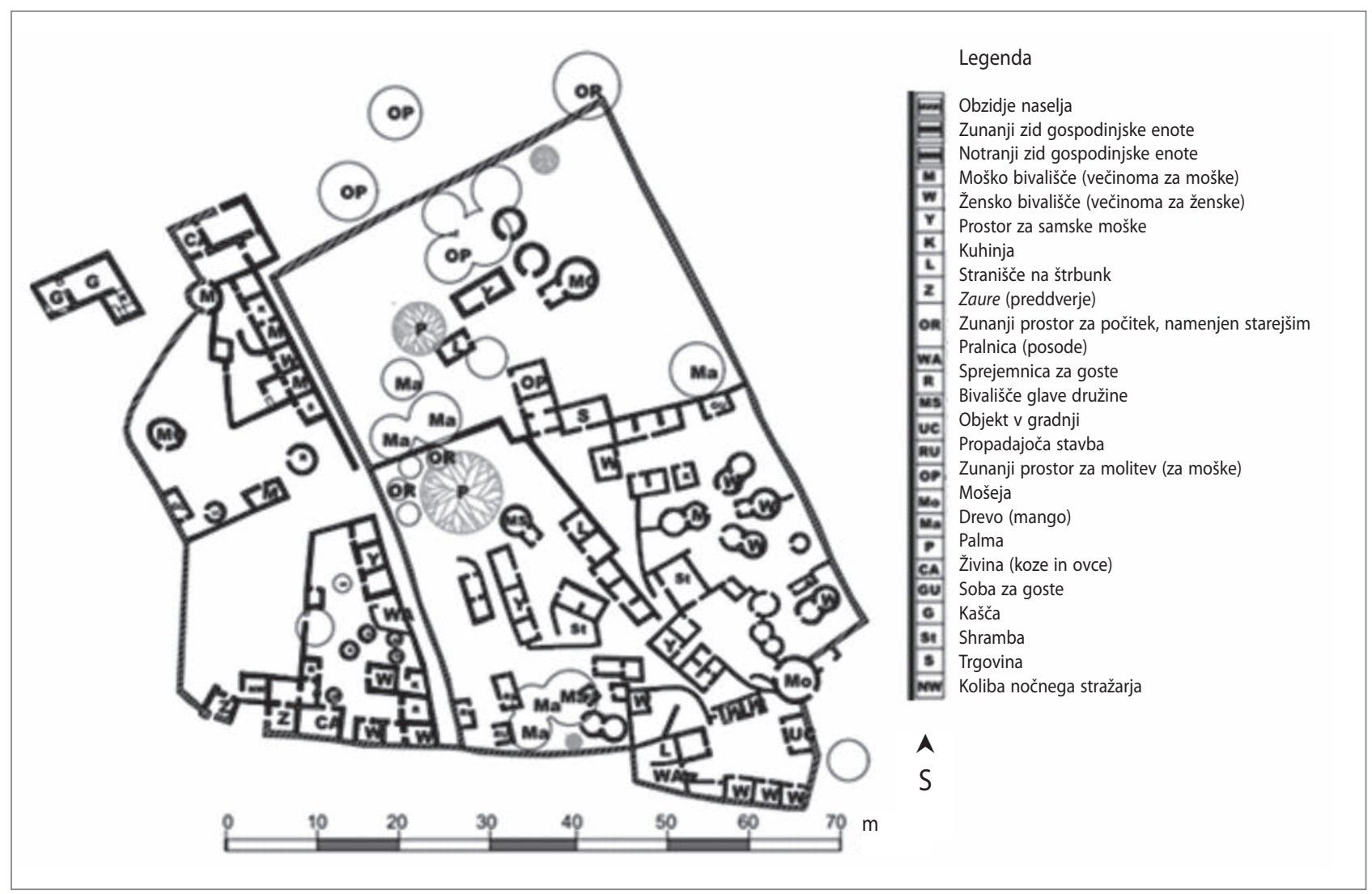

Slika 2: Prostorska ureditev in tloris havškega naselja (ilustracija: avtorja, na podlagi Moughtin, 1964, in lastnih opazovanj) 
močji, poraščenimi z redkim trnatim grmičevjem. Pred britansko kolonialno vladavino so imele havške države vzpostavljeno predkapitalistično gospodarstvo in dobro razvita upravna središča. Havsi so poznali raznoliko tehnologijo, ki so jo uporabljali pri raznih obrteh, kot sta lončarstvo in krašenje buč (Kirk-Green, 1961). Na opisanem geografskem območju se je Zaria, eno izmed večjih mest v nigerijski zvezni državi Kaduna, prej znano kot Zazzau, razvilo v eno izmed sedmih havških mestnih držav. Po podatkih nigerijskega popisa prebivalstva je imelo mesto leta 2006406.099 prebivalcev (Federal Office of Statistics, 2006). V mestu, v katerem prevladujejo Havsi, so razne ustanove in tržnice, njegovo gospodarstvo pa temelji na kmetijstvu (Mảaruf, 2019).

\subsection{Pojav značilne zasnove havških naselij}

V 14. stoletju sta imela trgovina čez Saharo in širjenje islama iz malijskega cesarstva ogromen vpliv na obliko havških naselij. Iz hierarhije podeželskih naselij se je razvila edinstvena zasnova, ki temelji na sistemu razširjenih družin, razdeljenem na več gospodinjskih enot $s$ pripadajočimi funkcionalnimi površinami. Na sliki 2 je prikazana značilna prostorska ureditev havškega naselja s posameznimi gospodinjskimi enotami (domačijami) in dvorišči. Naselje je ograjeno in sestavljeno iz več strnjenih domačij. Pri odločanju o notranji ureditvi naselja je bila ključna varnost. Zaria je dober primer havškega mesta, obdanega z obrambnim zidom, ki je bil zgrajen v 18. stoletju (Adeyemi, 2008). Zgoščenost gospodinjstev blizu tržnice kaže na obrambni slog havških naselij in prostorsko ureditev, ki omogoča druženje.

\subsection{Vpliv tradicionalne havške arhitekture na obliko naselij}

Povezava med tradicionalno havško arhitekturo in sodobno obliko naselij temelji na treh odločilnih dejavnikih: kulturi Havsov, okolju in podnebnem vplivu. Kultura Havsov temelji na zgodovini in tradiciji. Osredotoča se na sorodstvene vezi in družbeno strukturo ljudi (Madaua, 1968). Njihov način gradnje kaže vplive islama, pri čemer so prevladovali objekti ukrivljenih in stožčastih oblik s kupolasto streho iz blata (slika 3). Rapoport (1969) ugotavlja, da je avtohtona havška arhitektura znana po rebrastih obokih in kupolastih zunanjih zidovih stavb, ki omogočajo hitrejše odtekanje vode med nalivi. Poleg tega so bila posamezna bivališča včasih sestavljena iz enot jajčaste oblike, imenovanih tubali, s katerih je dež dobro odtekal. Med terenskimi opazovanji je bilo ugotovljeno, da so kupolaste strehe zgrajene iz blata, posušenega na soncu in na koncu ometanega, da je vse skupaj videti kot iz enega kosa (Beer in Higins, 2000). Posamezna domačija je sestavljena iz okroglih objektov, včasih so med temi tudi objekt $\mathrm{z}$ ravnimi robovi,

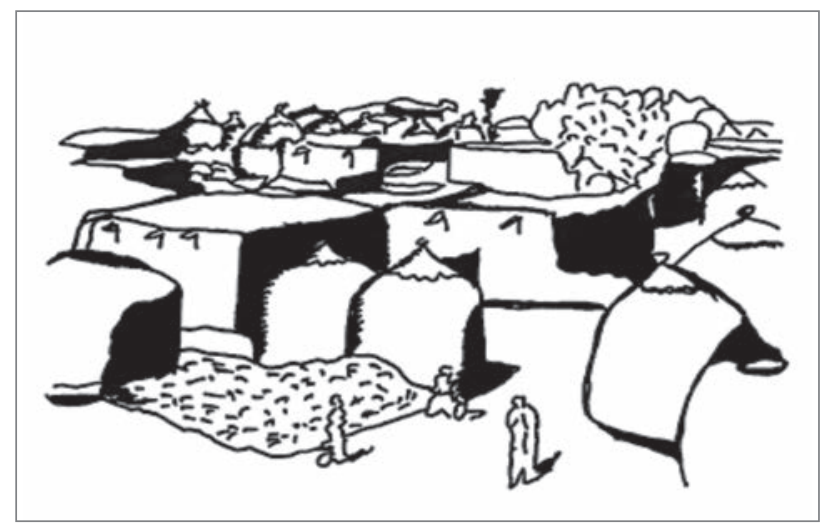

Slika 3: Havški način gradnje z značilnimi ukrivljenimi in stožčastimi oblikami (ilustracija: avtorja, na podlagi Rapoport, 1969)

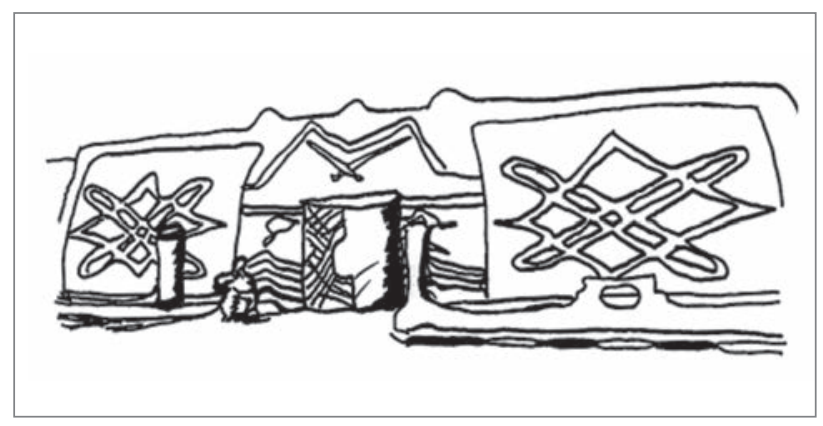

Slika 4: Značilne poslikave na vhodnem zidu (ilustracija: avtorja)

ki pa vseeno ne tvorijo popolne kvadrataste oblike. Objekti so med seboj povezani, vse pa obdaja zid (Friedrich, 1982).

\subsection{Vpliv podnebja in britanske kolonialne vladavine na tradicionalno zasnovo havških naselij v Zarii}

Zaria je na savanskem območju Zahodne Afrike, za katero je znacilno tropsko podnebje s toplim vremenom skozi vse leto. Deževna doba traja od marca do septembra, sušna pa od oktobra do februarja. Leta 2016 je povprečna dnevna temperatura znašala $25,6^{\circ} \mathrm{C}$, s povprečno količino padavin $117,6 \mathrm{~mm}$ in 69-odstotno povprečno relativno vlažnostjo. Zaradi takega podnebja je treba zasnovati tako gradnjo, ki blaži dnevno vročino in omogoča nočno hlajenje. Slamnate strehe se na primer uporabljajo kot okras in za zaščito zidov iz blata pred vročino in nalivi, $\mathrm{v}$ odprtinah pod hišami in kaščami pa $\mathrm{v}$ vročini in nalivih najdejo zavetje kokoši, psi in mačke. Opisani načini gradnje se v nekaterih tradicionalnih havških naseljih uporabljajo še danes (Beer in Anne, 1982). Drugo okrasje vključuje poslikave na vhodnem zidu (slika 4). Na delu obzidja, kjer je glavni vhod, je raznovrstno, močno poudarjeno okrasje, kar je še danes značilno za mnoga havška mesta, kot so Kano, Kazaure in Zaria. Tovrstna okrasna umetnost je del arhitekturne dediščine in jo je mogoče opaziti v številnih predelih Zarie. 


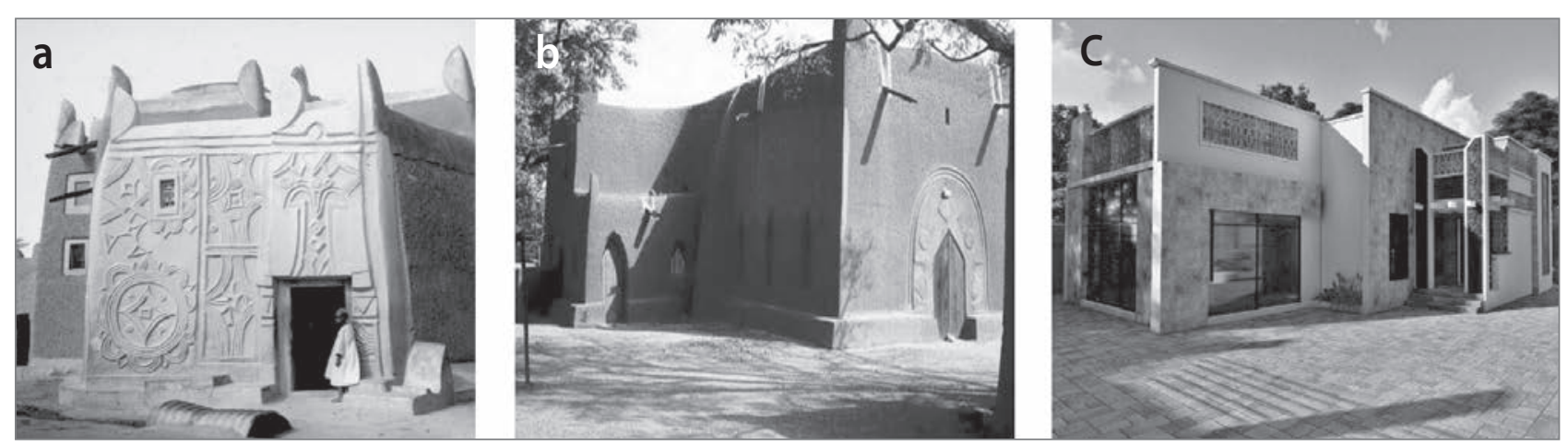

Slika 5: (a) primer tradicionalne havške arhitekture (foto: Isaac Samuel), (b) primer kolonialne havške arhitekture (foto: Isaac Samuel), (c) primer sodobne havške arhitekture (foto: Kalifa Rabiu)

Vključuje preproste trikotnike ter navpične, vodoravne in včasih okrogle like in vzorce. Začetki britanske vladavine v Nigeriji segajo v 18. stoletje, vrhunec pa je dosegla v 20. stoletju. V kolonialnem obdobju so se začele graditi stavbe sodobnih oblik, hkrati pa se so začeli spreminjati tudi pogledi na načrtovanje mest (slika 5).

Kolonialne oblasti so poleg tega v novih naseljih zunaj ograjenega mesta začele graditi posebna vladna stanovanjska območja za belce, ki so spodbujala sodoben način življenja in $\mathrm{v}$ katerih so prevladovali sodobni, obstojni gradbeni materiali, kot so cement, beton in jeklo. Zaradi tega so tudi prebivalci Zarie začeli drugače gledati na uporabo blata kot gradbenega materiala in pomen arhitekture v prostorski ureditvi domačij. Tako so tudi v Zarii začele nastajati betonske stavbe in tlakovane ceste. $\mathrm{Z}$ vidika zunanjega opazovalca je tradicionalna havška arhitektura razpeta med spremembami in sodobnim življenjem na eni strani ter kulturo in dediščino na drugi. $\mathrm{V}$ Zarii ni več moderno graditi hiš iz blatnih opek, še vedno pa je moderno okraševati vhode stavb v tradicionalnem havškem slogu (Adedokun, 2014).

V kolonialnem obdobju so Havsi začeli kolovoze in zidove iz blata, ki so obdajali bivališča, nadomeščati z ulično zasnovo. V tradicionalnem havškem naselju je vsak prostor ločen glede na rabo. Na primer, hiše muslimank, ki so morale bivati v ločenih prostorih in si ob izhodu zakrivati obraz, so bile urejene tako, da je imela vsaka ženska, ki je bila podrejena svojemu možu, svojo sobo. Vzorec je značilen tudi za druga afriška naselja, vendar so v Zarii sobe okrog dvorišča razporejene tako, da so moški in ženske med sabo ločeni. $\mathrm{V}$ naselje se vstopi skozi preddverje (zaure) - običajno je to koliba, v kateri sedijo moški in se pogovarjajo. Vsak družinski član ima neomejen dostop do dvorišča, kjer se lahko igrajo tudi otroci. Na robu dvorišča so kolibe za neporočene mlade moške in moške goste. Žena svoje prostore okrasi z darili, ki jih je prejela za doto, in drugimi osebnimi predmeti. $\mathrm{V}$ teh prostorih tudi spi skupaj s svojimi najstniškimi otroki, kar velja še danes. Ko je odraslemu moške$\mathrm{mu}$ dodeljen kos zemlje, najprej zgradi obzidje, vhodno kolibo ali preddverje in več kolib za spanje, odvisno od potreb. Ti objekti stojijo znotraj obzidja. Z obzidjem ograjene gospodinjske enote družin, povezanih s sorodstvenimi vezmi, običajno stojijo skupaj. Mreža obzidij ustvarja značilno zasnovo naselja, ki se na koncu spremeni v mesto. Oblikovanje mesta je proces, pri katerem kulturne, družbene, gospodarske, politične in fizične prvine vplivajo druga na drugo. Lynch in Rodwin (1958) ugotavljata, da urbane oblike nastajajo na podlagi izkušenj in so osnovne prvine človeških naselij, kulture in družbe. Razporeditev urbanih prostorov je torej ključni dejavnik družbenih in prostorskih ureditev. V Zarii urbane prvine običajno fizično in prostorsko vplivajo na družbena in gospodarska okolja, kar je značilno za sodobna mesta.

\section{Rezultati in razprava}

\subsection{Prehod iz tradicionalne Zarie v sodobno mesto}

Avtorja sta opravila intervjuje s 63 anketiranci, vključno s ključnimi posamezniki iz Zarie, da bi ugotovila, kaj menijo o vplivu tradicionalne havške arhitekture in zasnove naselij v mestu. Po mnenju 68 \% vprašanih (glej sliko 6) se je vloga tradicionalne havške arhitekture na sodobno zasnovo naselij zmanjšala, še vedno pa vpliva na obliko stavb in naselij. $32 \%$ vprašanih pa je navedlo, da na obliko stavb in naselij vplivajo drugi dejavniki, kot so sodobna načela urbanističnega oblikovanja in načrtovanja. $V$ zvezi z verskim vplivom na sodobno arhitekturo jih $52 \%$ meni, da je vera tako ali drugače vplivala na način gradnje v preteklosti, danes pa je njen vpliv manjši. $41 \%$ jih meni, da na obliko havških naselij vplivajo arhitekturni slogi zahodnega sveta, 7 \% pa, da nanjo vpliva mednarodna arhitektura, kar zmanjšuje tamkajšnji tradicionalni verski vpliv na obliko stavb in naselij. $\mathrm{Z}$ vidika prostorske ureditve in funkcionalne rabe prostora $65 \%$ vprašanih meni, da ima tradicionalna arhitektura še vedno velik vpliv, $32 \%$ jih je navedlo, da je njen vpliv zmeren, $3 \%$ pa, da je velik. To temelji na mnenju, da se pri sodobnem načrtovanju mest uporabljajo arhitekturni in urbanistični koncepti, kot so novi 


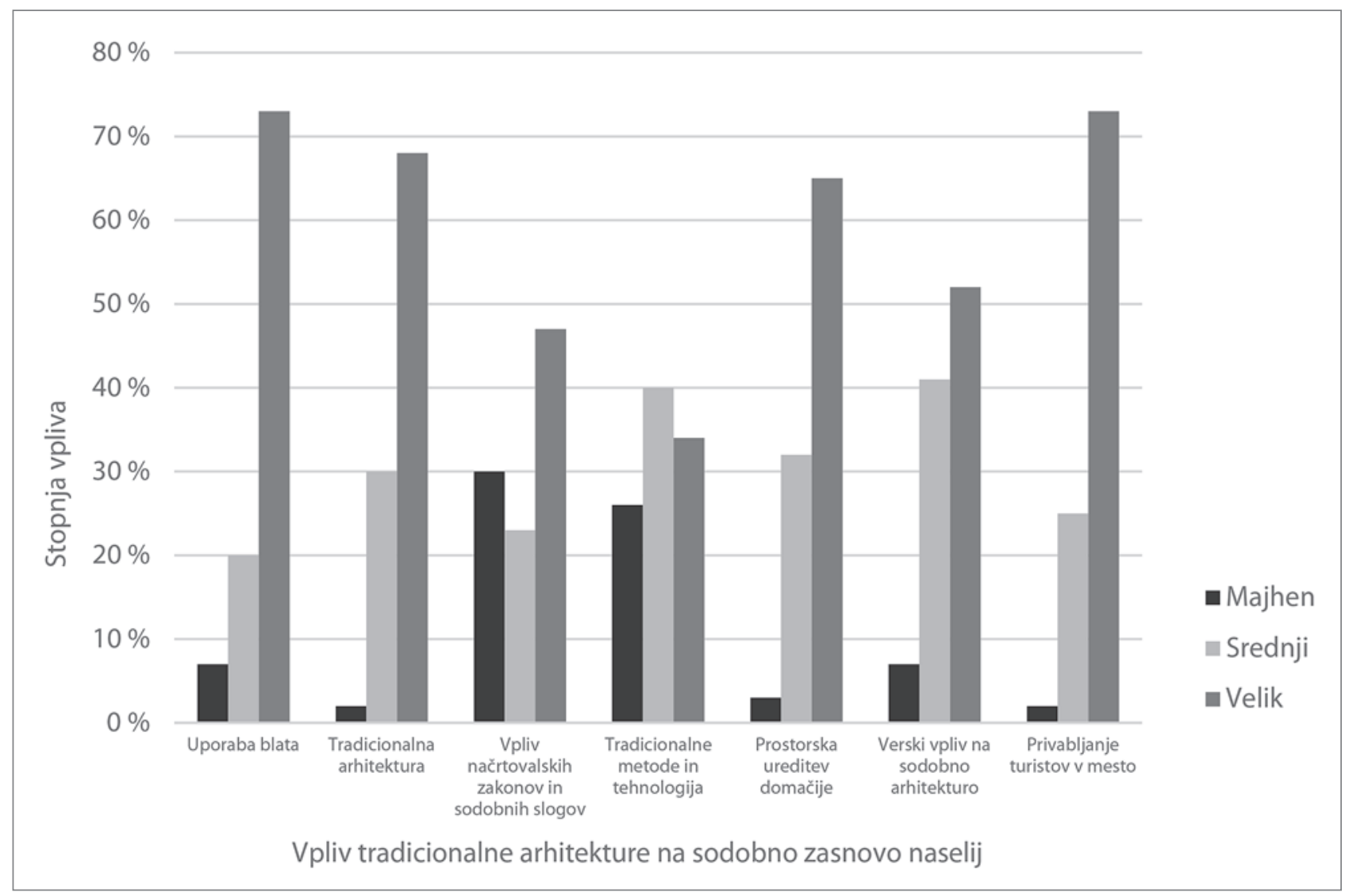

Slika 6: Mnenja anketirancev glede vpliva tradicionalne havške arhitekture (grafični prikaz: avtorja)

urbanizem, nova mobilnost, nova regionalizacija in pametna mesta. Izsledki se ujemajo z ugotovitvami raziskave, ki jo je opravil Akintoye (2010), in kažejo, da imajo glavne etnične skupine v Nigeriji bogato tradicijo, pri kateri kultura vpliva na obliko stanovanjskih stavb. Vpliv se izraža v različnih prvinah tradicionalnih hiš, vključenih v sodobno arhitekturno oblikovanje in načrtovanje mest (Bailey idr., 1977). Husukić in Zejnilović (2017: 17) ugotavljata, da »lahko arhitekturni ostanki ali razvaline v mestnem tkivu namesto nestabilnih enot postanejo gonilo kontinuitete«. To nakazuje potrebo po vključevanju stare in nove arhitekture v urbanistično oblikovanje in načrtovanje.

Raziskava je pokazala še, da se lahko tradicionalna prostorska ureditev havških naselij vključi v ureditev novih mestnih predelov, saj se tudi sodobno urbanistično oblikovanje in načrtovanje osredotočata na gospodarno rabo zemlje in materialov ter funkcionalno uporabo prostora. Zdi se, da je islam ključni dejavnik za ohranjanje tradicionalne havške arhitekture in naselij (Aluko, 2011). Pojav sodobne podobe mestnega prebivalca in dejstvo, da je vlada poskušala vključiti tradicijo $\mathrm{v}$ gradbene predpise, med anketiranci nista bila dobro sprejeta. Kljub temu je z vidika toplotnega udobja, oblike in podnebja blato še vedno pogosto uporabljen gradbeni material v Nigeriji (Evans, 1995; Danja idr., 2017). Večina anketirancev (73 \%) se je strinjala, da sta tradicionalna arhitektura Havsov in zasnova njihovih naselij vplivala na obliko stavb v mestu. Okraševanje pročelij in vhodov $s$ podobami mečev in polmeseca je značilna prvina ljudske arhitekture in dediščine, vidna na nekaterih stavbah v Zarii.

$65 \%$ anketirancev meni, da so na obliko stavb v Zarii vplivali kolonialni slog, uvedba sodobne gradbene zakonodaje v 19. in 20. stoletju ter naslednje okoliščine:

- zmanjšanje števila velikih tradicionalnih havških družinskih bivalǐ̌č zaradi uvedbe prostorske zakonodaje, ki je dajala prednost manjšim nuklearnim družinam $s$ hišo ter urejenim dvoriščem in parkiriščem;

- zaradi sodobne stanovanjske gradnje in prednosti ekonomije obsega se je v novem delu mesta zmanjšal vpliv havške arhitekture in zasnove naselij;

- upad rabe tradicionalnih oblik havških naselij zaradi uvedbe sodobnih gradbenih materialov, kot so cement, beton in jeklo, in ulične zasnove;

- manjša uporaba tradicionalnega okrasja, oblikovanega iz blata, in večja naklonjenost sodobnim materialom zaradi njihove lažje uporabe;

- slamnate strehe se nadomeščajo s strehami iz valovite pločevine, saj je uporaba sodobne strešne kritine veliko preprostejša od napornega pokrivanja streh s slamo. 
Preglednica 2: Dejavniki, ki podpirajo združevanje starih in novih oblik naselij, in njihov pomen

\begin{tabular}{ll}
\hline $\begin{array}{l}\text { Dejavnik } \\
\text { Prostorska strnjenost mestnih } \\
\text { območij }\end{array}$ & $\begin{array}{l}\text { Peč območij za pešce, manjša poraba energije, visoka kakovost življenja z vidika družabnih stikov, } \\
\text { dostop do komunalnih storitev, večji občutek pripadnosti skupnosti, manjša potreba po prevozu. }\end{array}$ \\
\hline Mobilnost & $\begin{array}{l}\text { Manjša potreba po prevozu, dostop do storitev, prikladno naravno okolje in površine, prijazne pešcem, } \\
\text { boljši javni prevoz. }\end{array}$ \\
\hline Gostota & $\begin{array}{l}\text { Dobra povezanost urbanih funkcij in prostorskih dejavnosti, strnjena gradnja, učinkovita raba prostora } \\
\text { in mestnih zemljišč, manj lastnikov avtomobilov in manjša potreba po prevozu. }\end{array}$ \\
\hline Mešana raba prostora & Varnost na ulicah, večja dostopnost, privlačne ulice, več ustvarjalnih stikov med sosedi. \\
\hline Raznolikost & $\begin{array}{l}\text { Bogate družbene in kulturne dejavnosti ter različna tradicionalna in verska prepričanja, ki spodbujajo } \\
\text { hodljivost in oblikovanje privlačnih mestnih krajin v bližini. }\end{array}$ \\
\hline Zeleni mestni razvoj & $\begin{array}{l}\text { Spodbujanje prilagoditev mikroklimatskim razmeram, zelene površine za otroke, odprti prostori za } \\
\text { druženje in spodbujanje participativnih metod prostorskega načrtovanja. }\end{array}$ \\
\hline
\end{tabular}

Vir: Dhingra in Chattopadhyay (2016)

\subsection{Prehod iz havških blatnih kolib v betonske stavbe}

Človek je pri gradnji blato zamenjal z betonom in jeklom zaradi njune trpežnosti, prikladnosti in prožnosti (Taylor, 1998; Chokor, 2005). Edinstvenost havške stanovanjske gradnje temelji na dostopnosti materialov in prostorski ureditvi domačij. Blato ni umetelno obdelano, kot so cementni zidaki. Havsi, zlasti tisti v Zarii, so najraje uporabljali drevesne veje, rdeči laterit in savansko travo, ki so bili dostopni v bližini. Ker pa laterit ni tako plastičen kot glina, so mu tradicionalni havški zidarji začeli dodajati travo, gnoj in zmlete plodove rožičevca, da bi izboljšali plastičnost blatnih zidakov. Ker je bilo blato povsod na voljo in zlahka dostopno, se je uporabljalo za gradnjo hiš, vendar je imel ta način gradnje številne slabosti, kot so neprožnost, nestabilni temelji in neodpornost proti eroziji. $\mathrm{Na}$ vedene težave se zdaj rešujejo z uporabo gradbenih materialov, kot je beton, cementni zidaki ali lomljen kamen (Rudofsky, 1964; Yiftachel, 1989). Zamenjava tradicionalnih gradbenih materialov ima vpliv na kulturno dediščino prebivalcev Zarie, ki se danes kaže v združevanju starih in novih oblik stavb.

\subsection{Vpliv zunanjih dejavnikov}

Na preobrazbo stavb in zasnove naselij v Zarii so delno vplivali tudi zunanji dejavniki, kot so vera (džihad), vsakdanje življenjske potrebe, okolje in potreba po varnosti. Zaradi preteklih in sedanjih družbenogospodarskih dejavnikov so začeli prebivalci Zarie značilnosti bivališč in oblike naselij dojemati z vidika sprememb in sodobnega načrtovanja mest. Podobno sta ugotovila tudi Kuvač in Schwai (2017: 11) v raziskavi o (re)konstrukciji prostorske identitete v soseskah Mađir v Banjaluki (Bosna in Hercegovina) in Ilsvika v Trondheimu (Norveška), v kateri sta podarila potrebo po upoštevanju $\gg$ zgodovinskih in osnovnih odnosov med ljudmi in krajem «.

\subsection{Vpliv prostorske ureditve tradicionalnih havških naselij}

Raziskava je pokazala, da sta tradicionalna havška arhitektura in zasnova naselij v Zarii uspevali zaradi okolja, ki je to omogočalo. Na havškem ozemlju sta bili razširjeni zaradi lokalno razpoložljivih in cenovno dostopnih gradbenih materialov ter njunega družbeno-kulturnega pomena. To je potrdila tudi večina anketirancev (73\%). Vpliv tradicionalne havške arhitekture in zasnove naselij je viden $\mathrm{v}$ ureditvi prostora in funkcij v sedanjih havških soseskah v Zarii, med drugim v ločenosti objektov in prostorov na posamezni domačiji, kar je družbenogospodarska posebnost. Urejenost domačij v sklenjene enote s pripadajočimi funkcionalnimi površinami izraža značilno zasnovo tradicionalnega havškega naselja, ki bi se lahko vključila $\mathrm{v}$ sodobne mestne gradbene projekte in načrte.

\subsection{Dejavniki, ki podpirajo združevanje starih in novih oblik naselij v Zarii}

Študija o Zarii se osredotoča na dejavnike, ki podpirajo združevanje tradicionalnega in sodobnega načrtovanja naselij. Njeni izsledki so pokazali, da se lahko prvine prostorske ureditve tradicionalnih naselij v Zarii delno vključijo v sodobno urbanistično oblikovanje in načrtovanje. Proučevani dejavniki vplivajo na trajnostni razvoj z družbenega, gospodarskega in okoljskega vidika (glej preglednico 2).

Zaria se je iz preprostega mesta z obzidjem razvila $\mathrm{v}$ konglomeracijo, sestavljeno iz treh glavnih delov: 1) starega dela mesta, obdanega z obzidjem, 2) nehavških stanovanjskih območij, zgrajenih v evropskem slogu, ki vključujejo tudi vladne urade in tržnice, ter 3) novega dela mesta, v katerem živijo druge, nehavške, etnične skupine. Kot navaja Mảaruf (2019), je bil vsak del ločena upravna in načrtovalska enota. Mestni načrt iz 


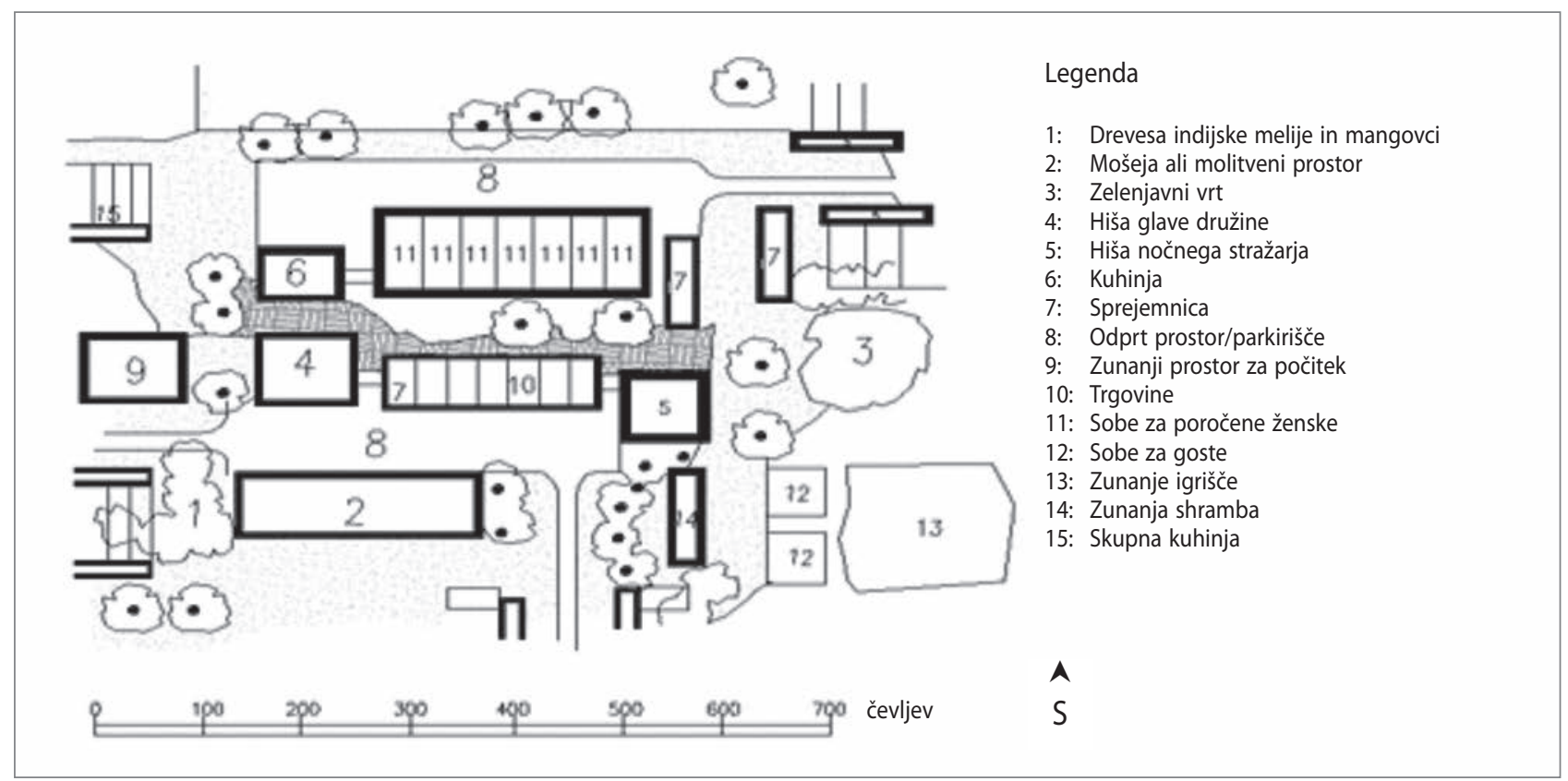

Slika 7: Vključitev tradicionalne zasnove naselja v zasnovo sodobnega mestnega predela (ilustracija: avtorja)
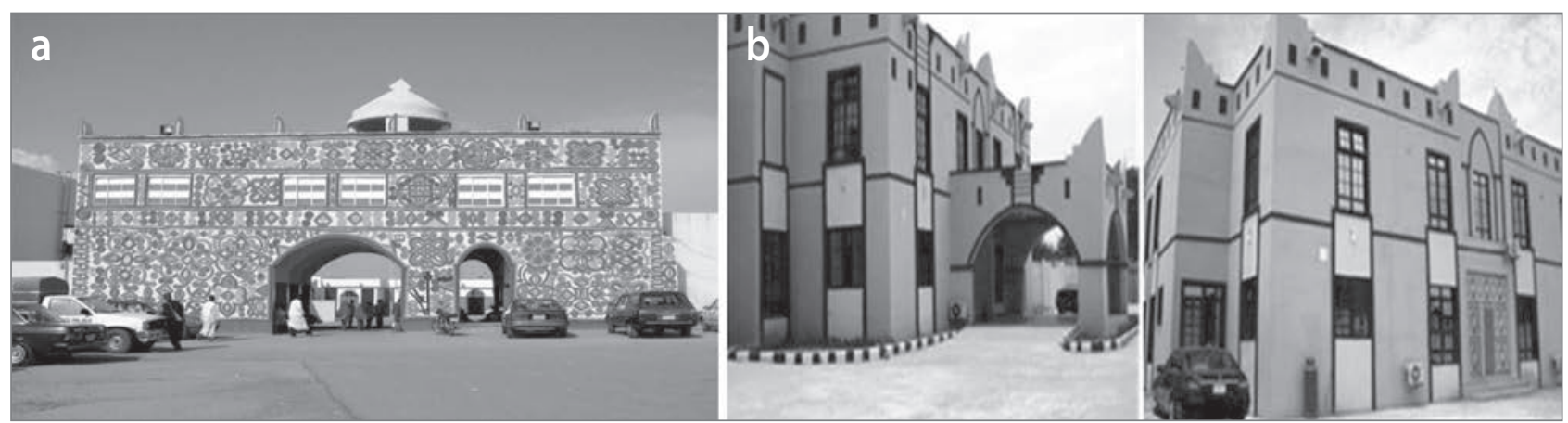

Slika 8: (a) tradicionalna havška arhitektura v severni Nigeriji, (b) sodobna havška arhitektura z zašiljenimi zaključki (zanko) na vrhu, ki dajejo tradicionalen videz (foto: Shiraz Chakera).

leta 1917 je nastal na podlagi niza načrtov, ki jih je leta 1914 predlagala kolonialna uprava, nato pa je bil leta 1918 in nato še leta 1939 znova popravljen in dopolnjen. Vse različice načrta so se osredotočale na glavna stanovanjska območja v evropskem slogu in z njimi povezano rabo zemljišč (Yigitcanlar idr., 2015).

\subsection{Uporaba tradicionalne zasnove naselij, značilne za Zario}

$\mathrm{V}$ tem poglavju je ponazorjeno, kako se lahko tradicionalna zasnova naselij, značilna za Zario, vključi v zasnovo novih mestnih predelov. Tradicionalni havški odprti prostor, imenovan dadali, je primerljiv z zelenimi ali parkovnimi površinami $\mathrm{v}$ novih mestnih predelih. Poleg tega se lahko sklenjene havške gospodinjske enote $s$ pripadajočimi funkcionalnimi površinami (domačije) v Zarii - zlasti njihov vhod ali preddverje, kjer za varnost prebivalcev skrbi vratar ali nočni stražar - primerjajo z zasnovo slepih ulic. Na sliki 7 je prikazan poskus vključitve prvin tradicionalnih havških naselij $\mathrm{v}$ zasnovo novih mestnih predelov (Jackson, 2005). To se sklada z ugotovitvijo predhodne raziskave, da sta urbanistično oblikovanje in načrtovanje »večdimenzionalna in kompleksna prvina, ki se lahko presoja simbolno ali z vidika oblike (forme), pri čemer je treba hkrati s posameznikovimi izkušnjami, vedenjskimi vzorci ter subjektivnimi vidiki in pomeni proučiti tudi fizične značilnosti, naravno okolje, rabo zemljǐ̌šc, prometne tokove in grajene oblike « (Rezafar in Turk, 2018: 24). Iz vpliva tradicionalnih naselij v Zarii se lahko veliko naučimo glede podobnosti in razlik v prostorski ureditvi naselij. Opaziti je mogoče mnoge sodobne primere vključevanja tradicionalnih oblik havških naselij in načrtovalskih načel v gradnjo, ti primeri pa se lahko uporabljajo tudi na splošno pri načrtovanju mest in upravljanju trajnostnega razvoja. Razlike in podobnosti z vidika dejavnikov, ki vplivajo 
Preglednica 3: Dejavniki, ki vplivajo na tradicionalno in sodobno zasnovo naselij v Zarii

\begin{tabular}{|c|c|c|c|c|}
\hline & Razlike & & Podobnosti & \\
\hline Dejavniki & Tradicionalna oblika & Sodobna zasnova & Tradicionalna oblika & Sodobna zasnova \\
\hline \multirow{4}{*}{$\begin{array}{l}\text { Prilagojenost } \\
\text { okolju }\end{array}$} & Gradnja na primerni lokaciji. & $\begin{array}{l}\text { Izbrana lokacija mora } \\
\text { izpolnjevati gradbene } \\
\text { zahteve. }\end{array}$ & $\begin{array}{l}\text { Primernost lokacije za } \\
\text { stanovanjsko rabo, poplavno } \\
\text { varno območje. }\end{array}$ & $\begin{array}{l}\text { Stanovanjska gradnja na } \\
\text { poplavno varnih območjih. }\end{array}$ \\
\hline & Lokalni gradbeni materiali. & $\begin{array}{l}\text { Uvoženi ali obdelani } \\
\text { gradbeni materiali. }\end{array}$ & Les iz bližnjih gozdov. & Brušen uvožen les. \\
\hline & $\begin{array}{l}\text { Upoštevanje sezonskih tem- } \\
\text { peraturnih sprememb. }\end{array}$ & $\begin{array}{l}\text { Primernost lokacije je } \\
\text { lahko odvisna od } \\
\text { konstrukcijskih zahtev. }\end{array}$ & $\begin{array}{l}\text { Sezonske temperature, } \\
\text { padavine in vetrovi lahko } \\
\text { vplivajo na orientacijo stavb. }\end{array}$ & $\begin{array}{l}\text { Na orientacijo stavb vplivajo } \\
\text { osončenost, prevladujoči } \\
\text { vetrovi in temperatura. }\end{array}$ \\
\hline & $\begin{array}{l}\text { Drevesa se ohranijo zaradi } \\
\text { sence. }\end{array}$ & $\begin{array}{l}\text { Drevesa se posadijo, kjer } \\
\text { je treba. }\end{array}$ & $\begin{array}{l}\text { Gradnja okoli obstoječih } \\
\text { dreves. }\end{array}$ & $\begin{array}{l}\text { Drevesa so posajena zato, da } \\
\text { opravljajo točno določeno } \\
\text { funkcijo. }\end{array}$ \\
\hline \multirow{3}{*}{ Oblika naselja } & $\begin{array}{l}\text { Kultura posamezne etnične } \\
\text { skupine. }\end{array}$ & $\begin{array}{l}\text { Povezovanje ne glede na } \\
\text { etnično skupino. }\end{array}$ & $\begin{array}{l}\text { Kulturni dejavniki družbenega } \\
\text { povezovanja. }\end{array}$ & $\begin{array}{l}\text { Povezovanje ljudi iz } \\
\text { najrazličnejših okolij. }\end{array}$ \\
\hline & $\begin{array}{l}\text { Na velikost stavb vplivata } \\
\text { funkcija in raba. }\end{array}$ & $\begin{array}{l}\text { Stavbe imajo lahko več } \\
\text { nadstropij. }\end{array}$ & $\begin{array}{l}\text { Na velikost stavbe vpliva } \\
\text { njena raba. }\end{array}$ & $\begin{array}{l}\text { Velikost stavbe je odvisna od } \\
\text { razpoložljivih sredstev. }\end{array}$ \\
\hline & $\begin{array}{l}\text { Strnjene stanovanjske } \\
\text { stavbe. }\end{array}$ & $\begin{array}{l}\text { Stanovanjska gradnja na } \\
\text { podlagi coniranja. }\end{array}$ & $\begin{array}{l}\text { Bolj postopna kot spontana } \\
\text { urbanizacija. }\end{array}$ & $\begin{array}{l}\text { Urbanizacija na podlagi } \\
\text { gradnje novih sosesk in } \\
\text { mestnih predelov. }\end{array}$ \\
\hline \multirow{3}{*}{ Arhitekturni slog } & $\begin{array}{l}\text { Podoben način gradnje za } \\
\text { vse vrste stavb. }\end{array}$ & $\begin{array}{l}\text { Način gradnje je } \\
\text { prilagojen vrsti stavbe. }\end{array}$ & Osnovne gradbene metode. & $\begin{array}{l}\text { Gradnja z uporabo } \\
\text { tehnologije. }\end{array}$ \\
\hline & Lokalni materiali. & $\begin{array}{l}\text { Uvoženi ali industrijski } \\
\text { materiali. }\end{array}$ & Lokalni gradbeni materiali. & Uvoženi ali lokalni materiali. \\
\hline & $\begin{array}{l}\text { Stavbni okras temelji na } \\
\text { običajih ali kulturnih } \\
\text { praksah. }\end{array}$ & $\begin{array}{l}\text { Stavbni okras temelji na } \\
\text { raziskavah in inovacijah. }\end{array}$ & $\begin{array}{l}\text { Stavbni okras kot izraz družbe } \\
\text { in kulture. }\end{array}$ & $\begin{array}{l}\text { Stavbni okras kot izraz } \\
\text { popularne kulture in infor- } \\
\text { macijske tehnologije. }\end{array}$ \\
\hline \multirow{3}{*}{$\begin{array}{l}\text { Prostorska } \\
\text { ureditev }\end{array}$} & $\begin{array}{l}\text { Razporeditev odprtih pro- } \\
\text { storov in funkcij na podlagi } \\
\text { družbenih in kulturnih } \\
\text { potreb. }\end{array}$ & $\begin{array}{l}\text { Razporeditev odprtih } \\
\text { prostorov na podlagi } \\
\text { znanstvenih izračunov. }\end{array}$ & $\begin{array}{l}\text { Razporeditev odprtih } \\
\text { prostorov na podlagi družbe- } \\
\text { nih potreb in dejavnosti. }\end{array}$ & $\begin{array}{l}\text { Razporeditev odprtih } \\
\text { prostorov na podlagi rabe } \\
\text { zemljišč in coniranja. }\end{array}$ \\
\hline & $\begin{array}{l}\text { Ureditev bivališč na podlagi } \\
\text { klanov, zakonskega stana in } \\
\text { potreb. }\end{array}$ & $\begin{array}{l}\text { Odprt prostor, namenjen } \\
\text { otrokom. }\end{array}$ & $\begin{array}{l}\text { Razporeditev bivališč } \\
\text { na podlagi trenutnih bivalnih } \\
\text { potreb. }\end{array}$ & $\begin{array}{l}\text { Razporeditev bivališč na } \\
\text { podlagi gostote prebivalcev. }\end{array}$ \\
\hline & $\begin{array}{l}\text { Razporeditev bivališč na } \\
\text { podlagi velikosti razširjenih } \\
\text { družin. }\end{array}$ & $\begin{array}{l}\text { Razporeditev bivališč na } \\
\text { podlagi potreb. }\end{array}$ & $\begin{array}{l}\text { Razporeditev bivališč na } \\
\text { podlagi stanovanjskih potreb. }\end{array}$ & $\begin{array}{l}\text { Razporeditev bivališč na } \\
\text { podlagi razvojnih in } \\
\text { poslovnih predlogov. }\end{array}$ \\
\hline
\end{tabular}

Vir: avtorja

na tradicionalno in sodobno zasnovo mestnih predelov v Zarii, so podobne tistim v raziskavah od drugod (Mandanipour, 1996; Boerefijn, 2016).

\section{Sklep}

Raziskava je pokazala, da tradicionalna havška arhitektura in zasnova naselij vplivata na prostorsko ureditev stanovanjskih sosesk v Zarii (Falahat, 2013). Ob upoštevanju dejavnikov, ki so podobni pri načrtovanju tako tradicionalnih kot novih mestnih predelov, se lahko tradicionalna oblika naselij vključi v zasnovo novih mestnih območij. Izsledki so poleg tega po- kazali, da uporaba cenejših gradbenih materialov, kot so mešanica laterita in ilovice, les, kamen in slama, ter oblikovalskih načel, ki omogočajo več zasebnosti in večje udobje, izvira iz tradicionalne havške arhitekture in zasnove naselij. Kljub temu tradicionalne zasnove naselij ni mogoče v celoti vključiti v načrte novih mestnih območij, saj morajo biti zemljišča formalno pridobljena. V preteklosti so se zemljišča v glavnem pridobivala na podlagi tradicionalnih sistemov, pri katerih uradna registracija lastninskih pravic ni bila potrebna, danes pa to ni več mogoče. Da bi se arhitektura in oblika naselij, značilna za Zario, lahko uporabljali tudi drugod, morata ustrezati posameznemu družbeno-kulturnemu okolju. Pri tem se ne sme zanemariti vpliva modernizacije, zavedati pa se je treba tudi pomena me- 
šanja tradicionalnih in sodobnih konceptov arhitekture in načrtovanja naselij. Za boljše razumevanje okvira za povezovanje obeh modelov so potrebne nadaljnje raziskave. Tradicionalna naselja, tudi naselja Havsov v Zarii, izražajo želje ljudi, te želje pa temeljijo na družbenih, gospodarskih, izobraževalnih, verskih in kulturnih vrednotah. Urbanisti, arhitekti in investitorji bi lahko proučili, kako lahko tradicionalno arhitekturo in druge oblike kulturne dediščine vključijo v načrte novih naselij, da bi okrepili povezanost skupnosti in pomen dedišcine ter zagotovili primere dobre prakse pri urbanističnem oblikovanju in načrtovanju.

Peter Bikam, University of Venda, School of Environmental Sciences, Department of Urban and Regional Planning, Thohoyandou, Južnoafriška republika

E-naslov: peter.bikam@univen.ac.za

James Chakwizira, University of Venda, School of Environmental Sciences, Department of Urban and Regional Planning,

Thohoyandou, Južnoafriška republika

E-naslov: james.chakwizira@univen.ac.za

\section{Viri in literatura}

Adedokun, A. (2014): Incorporating traditional architecture into modern architecture: Case study of Yoruba traditional architecture. British Journal of Humanities and Social Sciences, 11(1), str. 39-45.

Adeyemi, A. E. (2008): Meaning and relevance in Nigerian traditional architecture: The dialectics of growth and change. Public Lecture Series, 1(21), str. 1-33.

Akintoye, A. S. (2010): A history of the Yoruba people. Dakar, Amalion Publishing.

Aluko, O. (2011): Functionality of the town planning authorities in effecting urban and regional planning laws and control in Nigeria: The case of Lagos State. African Research Review, 5(6), str. 156-171. DOI: 10.4314/afrrev.v5i6.14

Astrolabe, A. M. O. (2002): Architecture in Nigeria and practice for sustainable environmental development. A comparative study of modern and indigenous housing strategies. Journal of the Nigerian Institute of Architects, 2(1), str. 261-272.

Ayodele, E. I., in Odeyale, T. O. (2019): Designing for cultural revival: African housing in perspective, space and culture, str. 1-8. DOI: $10.1177 / 1206331218825432$

Bailey, J. W., Heyden, D., in Gendrop, P. (1977): Pre-Columbian architecture of Mesoamerica. V: Nervi, P. L. (ur.): History of world architecture series. New York, Harry N. Abrams. DOI: 10.2307/776099

Barau, A. S., Maconachie, R., Ludin, A. M. N., in Abdulhamid, A. (2015): Urban morphology dynamics and environmental change in Kano, Nigeria. Land Use Policy, 42, str. 307-317.

DOI: 10.1016/j.landusepol.2014.08.007

Beer, A. R., in Anne, R. (1982): The external environment of housing areas. Built Environment, 8(1), str. 25-29.

Beer, A. R., in Higgins, C. (2000): Environmental planning for site development: A manual for sustainable local planning and design. New York, Routledge.
Boerefijn, W. (2016): About the ideal layout of the city street in the twelfth to sixteenth centuries: The myth of the renaissance in town building. Journal of Urban History, 42(5), str. 938-952. DOI: 10.1177/0096144214566983

Buchanan, K. M., in Pugh, C. J. (1955): Land and people in Nigeria. London, Hodder \& Stoughton.

Chokor, B. A. (2005): Changing urban housing form and organization in Nigeria: lesson for community planning. Planning Perspectives, 20(1) str. 69-96. DOI: 10.1080/0266543042000300546

Danja, I. I., Dalibi, G. S., in Safarov. A. (2017): Factors shaping vernacular architecture of Northern Nigeria. Journal of Building and Sustainability, 1(1), pp. 36-47

Deckro, F. R., in Hebert, E. J. (2003): Modeling diminishing returns in project resource planning. Computers and Industrial Engineering, 44(1), str. 19-33. DOI: 10.1016/S0360-8352(02)00182-1

Dhingra, M., in Chattopadhyay, S. (2016): Advancing smartness of traditional settlements-case analysis of Indian and Arab old cities. International Journal of Sustainable Built Environment, 5(2), str. 549-563. DOI: 10.1016/j.jijsbe.2016.08.004

Denyer, S. (1978): African traditional architecture. London, Heineman Educational Books.

Dmochowski, R. Z. (1990): An introduction to Nigerian traditional architecture, 1-3. Lagos, The National Commission for Museums and Monuments.

Dobronravin, N. (2013): „Classical Hausa« glosses in a nineteenth-century Qur'anic manuscript: A case of »translational reading in Sudanic Africa? Journal of Qur'anic Studies, 15(3), str. 84-122. DOI: $10.3366 /$ jqs.2013.0115

Evans, B. (1995): Experts and environmental planning. Aldershot, ZK, Avebury.

Falahat, S. (2013): New town versus old town: A study on urban pattern and energy efficiency. Berlin, Universitätsverlag TUB.

Federal Office of Statistics (2006): Population census. Abuja.

Friedrich, S. W. (1982): Traditional housing in Africa cities. A comparative study of houses in Zaria, Ibadan and Marrakech. New York, John Wiley and Sons.

Husukić, E., in Zejnilović, E. (2017): Okoljska estetika Sarajeva: mesto, ki ga oblikujejo spomini. Urbani izziv, 28(1), str. 17-27. DOI: 10.5379/urbani-izziv-2017-28-01-002

Hutchison, D., in Sterbenz, G. J. P. (2018): Architecture and design for resilient networked systems. Computer Communications, 131(2018), str. 13-21. DOI: 10.1016/j.comcom.2018.07.028

Ibrahim, R. (2015): Elements of traditional urban form in the Arab world. Dostopno na: https://www.linkedin.com/pulse/elements-traditional-urban-form-arab-world-rafik-ibrahim (sneto: 19. 10. 2015).

Jackson, M. S. (2005): Cape colonial architecture, town planning, and the crafting of modern space in South Africa. Africa Today, 51(4), str. 33-54. DOI: 10.1353/at.2005.0042

Kirk-Green, A. (1961): Decorated houses in Zaria. Nigeria Magazine, 68, str. 52-78.

Kuvač, I., in Schwai, M. (2017): Tri prvine konstrukcije prostorske identitete v soseskah Mađir v Banjaluki (Bosna in Hercegovina) in Ilsvika v Trondheimu (Norveška). Urbani izziv, 28(1), str. 5-16. DOI: 10.5379/urbani-izziv-2017-28-01-001 
Lynch, K., in Rodwin, L. (1958): A theory of urban form. Journal of the American Institute of Planners, 24(4), str. 201-214. DOI: 10.1080/01944365808978281

Ma'aruf, S. (2019): The paradox of post-colonial urban growth in the city of Zaria, Nigeria. Journal of Geography and Regional Planning, 12(1), str. 1-9. DOI: 10.5897/JGRP2018.0714

Madaua, I. (1968): Hausa customs. Zaria, Nigerija, Northern Nigerian Publishing Company.

Mandanipour, A. (1996): Design of urban space: An enquiry into a socio-spatial process. New York, John Wiley \& Sons.

Markus, B. (2016): Review of courtyard house in Nigeria: Definitions, history, evolution, typology, and functions. AFRREV STECH: An International Journal of Science and Technology, 5(2), str. 103-117. DOI: $10.4314 /$ stech.v5i2.8

Moughtin, J. C. (1964): The traditional settlements of the Hausa people. Town Planning Review, 35(1), str. 21-22. DOI: 10.3828/tpr.35.1.y03303u5115t1711

Narayanan, Y. (2015): Religion, heritage and the sustainable city: Hinduism and urbanisation in Jaipur. London, Routledge.

DOI: 10.4324/9780203750797

Olotuah, A. O. (2000): The Challenge of housing in Nigeria. V: Akinbamijo, O. B., Fawehinmi, A. S., Ogunsemi, D. R., in Olotuah, A. O. (ur.): Effective Housing in 21st Century Nigeria, Akure, str. 16-21, Environmental Forum, Federal University of Technology, Department of Architecture, Nigeria.

Rapoport, A. (1969): House form and culture. Englewood Cliffs, NJ, Prentice-Hall.

Rezafar, A., in Turk, S. S. (2018): Oblikovalski dejavniki v estetski presoji novozgrajenih okolij in njihova vključenost v zakonodajo: primer Istanbula. Urbani izziv, 29(2), str. 22-33.

DOI: 10.5379/urbani-izziv-2018-29-02-002

Rowan, K. R. (1981): Formal and spatial variations in a traditional wall city of Zaria, Nigeria. Magistrsko delo. Cambridge, MA, Massachusetts Institute of Technology, Faculty of Architecture.

Royse, D., Dhooper, S., in Rompf, E. (2007): Field instruction: A guide for social work students. 5. izd. Boston, Pearson Education.

Rudofsky, B. (1964): Architecture without architects: A short introduction to non-pedigreed architecture. New York, Museum of Modern Art.

Taylor, A. J. (1998): Domestic agenda setting, 1947-1994. Legislative Studies Quarterly, 23(3), str. 373-397. DOI: 10.2307/440359

Yiftachel, O. (1989): Towards a new typology of urban planning theories. Environment and Planning, 16(1), str. 23-39. DOI: 10.1068/b160023

Yigitcanlar, T., Kamruzzaman, M., in Teriman, S. (2015): Neighborhood sustainability assessment: Evaluating residential development sustainability in a developing country context. Sustainability, 7(3), str. 25702602. DOI:10.3390/su7032570 